Check for updates

Cite this: New J. Chem., 2017, 41,6540

Received 28th April 2017, Accepted 2nd June 2017 DOI: 10.1039/c7nj01423f rsc.li/njc

\title{
Efficiency of photoinduced electron transfer in mono- and di-nuclear iridium complexes: a comparative study
}

\begin{abstract}
Sourav Kanti Seth, Parna Gupta and Pradipta Purkayastha (D)*
Iridium complexes have been recognized as the most widely used class of emitters because of their efficient spin-orbit coupling and hence relaxation of the spin selection rule. The strong phosphorescence of the $\operatorname{Ir}\left(\right.$ III) complexes is induced by the triplet metal-to-ligand charge transfer $\left({ }^{3} \mathrm{MLCT}\right)$. However, there are significant differences in the photophysical and electrochemical properties of the mono- and dinuclear Ir(III) complexes. Photoinduced energy and electron transfer (PET) is frequently observed in supramolecular Ir(III) cyclometalated complexes. Herein, we synthesized a mononuclear and a dinuclear $\operatorname{Ir}(\mathrm{II})$ complex $\left(\left[\mathrm{Ir}(\mathrm{ppy})_{2}(\mathrm{fmp})\right]\left[\mathrm{PF}_{6}\right]\right.$ and $\left[\left\{\mid \mathrm{r}(\mathrm{ppy})_{2}\right\}_{2}\left(\mathrm{H}_{2} \mathrm{bpib}\right)\right]\left[\mathrm{PF}_{6}\right]_{2}$, represented by $\mathbf{1}$ and $\mathbf{2}$ in the text, respectively) to compare their PET efficiencies. Spectroscopic and electrochemical studies reveal that 1 (consisting of a single iridium center) acts as a better electron donor as compared to $\mathbf{2}$ (consisting of two iridium centers) during PET.
\end{abstract}

\section{Introduction}

Cyclometalated iridium(III) complexes are well known for their rich photochemical and photophysical properties. ${ }^{1,2}$ These complexes show properties of organic light-emitting diodes, ${ }^{3-6}$ have applications in photovoltaic cells,,${ }^{7,8}$ and are used as biological labeling reagents ${ }^{9,10}$ because they possess high luminescence quantum yields and long excited state lifetimes. Iridium complexes have been recognized as the most widely used class of emitters because of their efficient spin-orbit coupling and hence relaxation of the spin selection rule. The strong phosphorescence of the $\operatorname{Ir}($ III) complexes is induced by the triplet metal-toligand charge transfer $\left({ }^{3} \mathrm{MLCT}\right)$, reflecting the character of both the metal centre and the organic ligand. ${ }^{11}$

Some phosphorescent dinuclear Ir(III) complexes show high luminescent efficiencies and good electroluminescent abilities. Therefore, highly phosphorescent dinuclear Ir(III) complexes have been synthesized and fully characterized. However, significant differences in the photophysical and electrochemical properties of the mono- and dinuclear complexes have recently been reported. Yang et al. showed that the key factor in determining the photophysical and electrochemical properties of dinuclear complexes is their unique molecular orbital spatial distribution pattern. ${ }^{6}$ They also noted that the efficiency of the organic lightemitting diode (OLED) constructed from the dinuclear iridium(III)

Department of Chemical Sciences, Indian Institute of Science Education and Research (IISER) Kolkata, Mohanpur 741246, WB, India.

E-mail: ppurkayastha@iiserkol.ac.in complex was much higher than of that constructed with the corresponding mononuclear counterpart.

Photoinduced energy and electron transfer processes are frequently observed in supramolecular Ir(III) cyclometalated complexes. ${ }^{12-14}$ It is also apparent that these polynuclear complexes possess enhanced extinction coefficients as compared to their mononuclear analogues. ${ }^{15,16}$ Spin-orbit coupling is facilitated by the presence of additional metal centers that, in turn, enhance the radiative rate constant and hence increase the efficiency of phosphorescence. ${ }^{4,17}$ In the semi-classical electron transfer (ET) theory, the reaction rates are governed by three principal parameters: (i) electronic coupling between the donor and acceptor, (ii) the change in the reaction free-energy $\left(\Delta G^{\circ}\right)$, and (iii) the extent of solvation accompanying the ET reaction. ${ }^{18}$ Moreover, ET rates can be limited by the dynamics of nuclear motion through the frequency factor $\nu_{\mathrm{N}}$.

Through extensive literature search, we could hardly find any reports on $\mathrm{Ru}$ or Re complexes with the simultaneous presence of fmp/ppy or $\mathrm{H}_{2} \mathrm{bpib} /$ ppy ligands as used in the present study. However, reports on Ru complexes with fmp/bpy or fmp/phen and $\mathrm{H}_{2}$ bpib/phen or $\mathrm{H}_{2}$ bpib/bpy ligands are available. ${ }^{19-21}$ It is inappropriate to compare the reported Ir and the Ru complexes of the present case because ppy acts as a cyclometalating ligand in our Ir complexes, whereas bpy/phen has been used for the Ru complexes. However, an overall comparison of their properties can be made. The Ru complexes show absorption maxima at around $280 \mathrm{~nm}\left(\varepsilon \approx 6 \times 10^{4} \mathrm{M}^{-1} \mathrm{~cm}^{-1}\right)$ and $370 \mathrm{~nm}(\varepsilon \approx 4 \times$ $10^{4} \mathrm{M}^{-1} \mathrm{~cm}^{-1}$ ) due to the $\pi-\pi^{*}$ transition and at around $460 \mathrm{~nm}$ $\left(\varepsilon \approx 2 \times 10^{4} \mathrm{M}^{-1} \mathrm{~cm}^{-1}\right)$ attributed to ${ }^{1}$ MLCT. The Ir complexes 

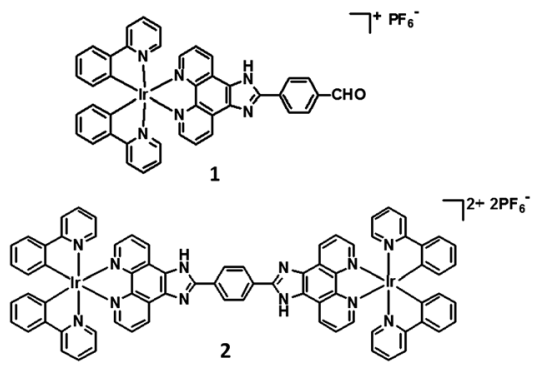

Scheme 1 Structures of the 1 ([Ir(ppy $\left.\left.)_{2}(f m p)\right]\left[P F_{6}\right]\right)$ and $2\left(\left[\left\{\operatorname{lr}(p p y)_{2}\right\}_{2^{-}}\right.\right.$ $\left(\mathrm{H}_{2}\right.$ bpib)] $\left.\left[\mathrm{PF}_{6}\right]_{2}\right)$ complexes.

show similar absorption bands at around $280 \mathrm{~nm}$ due to $\pi-\pi^{*}$ transition, and $370 \mathrm{~nm}\left(\varepsilon \approx 6 \times 10^{4} \mathrm{M}^{-1} \mathrm{~cm}^{-1}\right)$ and $470 \mathrm{~nm}$ $\left(\varepsilon \approx 6 \times 10^{3} \mathrm{M}^{-1} \mathrm{~cm}^{-1}\right.$ ) bands are considered to be due to ${ }^{1} \mathrm{LC} /{ }^{1} \mathrm{MLCT}$ (LC = ligand centred, MLCT $=$ metal-to-ligand charge transfer) and $\mathrm{MC}$ (metal centred) transitions, respectively. ${ }^{22}$ Differences in the molar extinction coefficients $(\varepsilon)$ in the visible region of the spectrum make the $\mathrm{Ru}$ analogues better visible light absorbers. Moreover, higher spin-orbit coupling constant of $\operatorname{Ir}\left(3909 \mathrm{~cm}^{-1}\right)$ makes intersystem crossing easier as compared to that of $\mathrm{Ru}\left(1042 \mathrm{~cm}^{-1}\right) .^{22}$ This makes Ir a better candidate for a more populated triplet excited state than its $\mathrm{Ru}$ analogue. Despite comparable triplet excited state lifetimes for both types of complexes (1-2 $\mu \mathrm{s})$, emission quantum yields for the $\mathrm{Ir}$ complexes are higher than those for the $\mathrm{Ru}$ complexes. $^{23,24}$ Moreover, the more populated, long-lived triplet excited state is better for efficient electron transfer than the less populated triplet excited state. Cyclic voltammogram shows that the Ir centres $\left(\mathrm{Ir}^{3+} / \mathrm{Ir}^{4+}\right)$ more easily oxidize $(\sim 1.20-1.25 \mathrm{~V})$ than the $\mathrm{Ru}$ centres $\left(\mathrm{Ru}^{2+} / \mathrm{Ru}^{3+} \sim 1.30-1.40 \mathrm{~V}\right)$ in the ground state. ${ }^{25}$

As light harvesting building blocks, Ir(III) complexes can transform solar energy into electrical energy through ultrafast ET. Hence, these potential candidates for energy harvesting are worth investigating through physicochemical studies. We have chosen two Ir(III) complexes, one mononuclear and one dinuclear (1 and 2 in Scheme 1), to compare their photoinduced electron transfer (PET) efficiencies. Spectroscopic and electrochemical studies reveal that $\mathbf{1}$ (consisting of a single iridium centre) acts as a better electron donor as compared to 2 (consisting of two iridium centres) during PET.

\section{Results and discussion}

The two Ir(III) complexes, a mononuclear and a dinuclear (1 and 2), were compared in terms of PET. Complex 1 was synthesized using a mixture of $\left[\operatorname{Ir}(\mathrm{ppy})_{2} \mathrm{Cl}\right]_{2}$, methanol, dichloromethane, and acetonitrile in appropriate proportions and refluxing it for $5 \mathrm{~h}$ at $90{ }^{\circ} \mathrm{C}$, and then, a reddish orange solution was obtained. To synthesize complex 2 , a mixture of $\left[\operatorname{Ir}(\mathrm{ppy})_{2} \mathrm{Cl}\right]_{2}$, $2(0.1 \mathrm{mmol})$, and acetonitrile/dichloromethane $(1: 1 \mathrm{v} / \mathrm{v})$ was refluxed for $4 \mathrm{~h}$ at $90{ }^{\circ} \mathrm{C}$ to obtain an orange coloured mixture. The mixture was cooled down to room temperature and the solvent was evaporated using a rotary evaporator. Both complexes were precipitated by adding potassium hexafluorophosphate
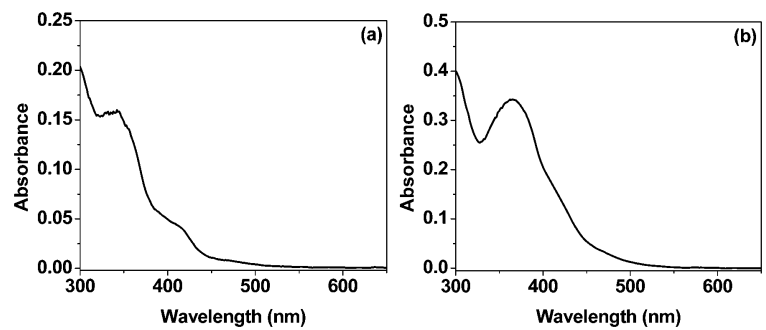

Fig. 1 Absorption spectra of the $1: 1 \mathrm{H}_{2} \mathrm{O}$-acetonitrile solutions of $\mathbf{1}$ and $\mathbf{2}$. The concentration of both complexes is $20 \mu \mathrm{M}$.

$\left(\mathrm{KPF}_{6}\right)$ in dichloromethane-methanol 1:1 mixture at room temperature and purified by silica gel column chromatography. ${ }^{26}$

The systems in the present study consisted of TEOA as the sacrificial donor, complex $\mathbf{1}$ or $\mathbf{2}$ as the photosensitizer, and methyl viologen dichloride $\left(\mathrm{MVCl}_{2}\right)$ as the electron acceptor. The absorption spectra of the complexes show two intense bands at around $280 \mathrm{~nm}$ and $360 \mathrm{~nm}$ and one weak broad band peaking at around $465 \mathrm{~nm}$ in 1:1 acetonitrile-water (Fig. 1). The band at $280 \mathrm{~nm}$ is attributed to the spin-allowed $\pi-\pi^{*}$ ligand-to-ligand charge transfer ( $\left.{ }^{1} \mathrm{LLCT}\right)$, whereas those at $360 \mathrm{~nm}$ and $465 \mathrm{~nm}$ are mainly due to ${ }^{1} \mathrm{MLCT}$ and $\mathrm{d}-\mathrm{d}$ transitions in the metal centre/s (MC). ${ }^{26}$ The molar extinction coefficient $\left(\varepsilon_{371}=6.6 \times\right.$ $\left.10^{4} \mathrm{M}^{-1} \mathrm{~cm}^{-1}\right)$ for 2 is almost twice that of $1\left(\varepsilon_{340}=3.1 \times\right.$ $10^{4} \mathrm{M}^{-1} \mathrm{~cm}^{-1}$ ) in acetonitrile.

Interestingly, irradiating the solutions of the individual complexes, added with the sacrificial electron donor and the acceptor, with the radiation of wavelength $370 \mathrm{~nm}$ turns the light yellow solution blue. This produces stable methyl viologen radical cations $\left(\mathrm{MV}^{\bullet+}\right)$ (see later) that absorb at $605 \mathrm{~nm}$ (Fig. 2). ${ }^{27-29}$ Fig. 2(c) shows that this phenomenon (formation of $\mathrm{MV}^{\bullet+}$ ) initially occurs faster in 2, but despite a slower start, the radical cation formation becomes faster in $\mathbf{1}$ over time and overtakes that observed in 2 . The sacrificial electron donor
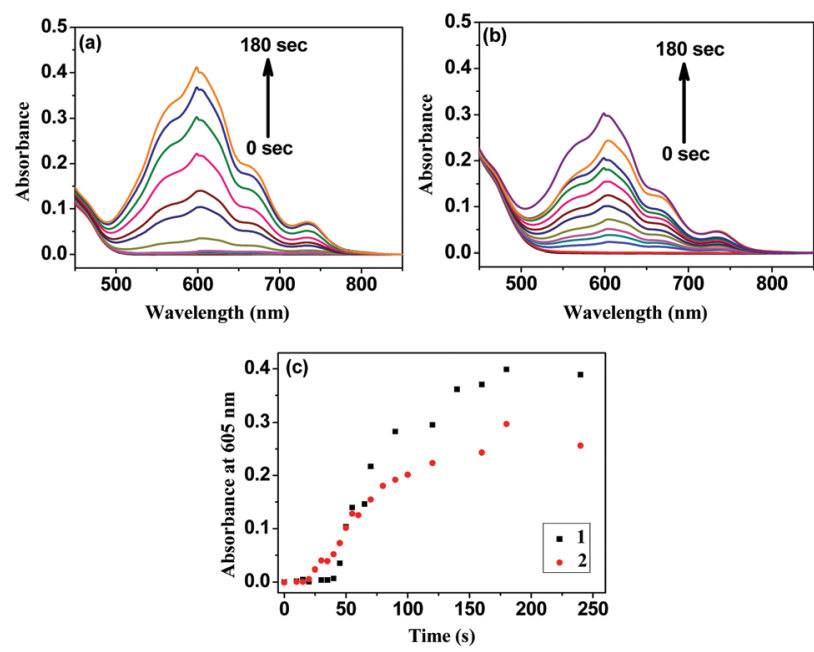

Fig. 2 Absorption spectra of the solutions containing (a) $20 \mu \mathrm{M}$ of $\mathbf{1}$, $625 \mu \mathrm{M}$ of TEOA, and $100 \mu \mathrm{M}$ of $\mathrm{MV}^{2+}$, and (b) $20 \mu \mathrm{M}$ of $2,625 \mu \mathrm{M}$ of TEOA, and $100 \mu \mathrm{M}$ of $\mathrm{MV}^{2+}$ with different light exposure times at wavelength $370 \mathrm{~nm}$; (c) comparative plots of absorbance at $605 \mathrm{~nm}$ with time. 

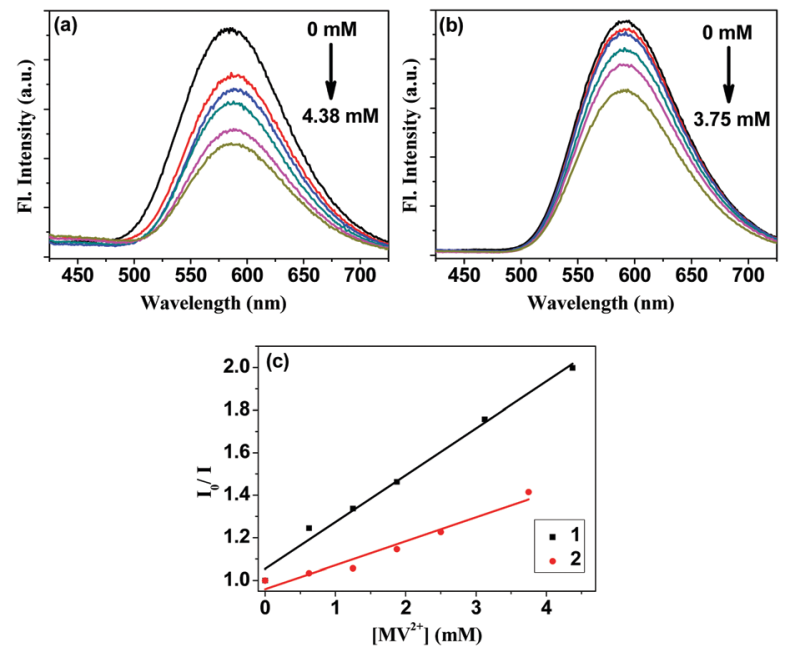

Fig. 3 Quenching of fluorescence of $20 \mu \mathrm{M}$ (a) 1 and (b) 2 added with $625 \mu \mathrm{M}$ TEOA and $0-4.375 \mathrm{mM}$ of $\mathrm{MV}^{2+}$; (c) Stern-Volmer quenching plots for the two complexes.

TEOA partially neutralizes the overall molecular charges of $\mathbf{1}$ and 2 and helps the acceptor $\mathrm{MV}^{2+}$ approach them to facilitate electron transfer. The slower electron transfer in the bimetallic complex 2 can be presumed to be due to lesser approachability of the $\mathrm{MV}^{2+}$ cations.

A similar trend was observed for the quenching of the fluorescence of $\mathbf{1}$ and $\mathbf{2}$ in the presence of TEOA and $\mathrm{MV}^{2+}$ (Fig. 3). Both complexes show a broad emission peaking at $590 \mathrm{~nm}$ upon excitation at $370 \mathrm{~nm}$ in 1:1 acetonitrile-water. Previous studies showed that the presence of iridium in a compound eases intersystem crossing (ISC), rendering a populated triplet state $\left({ }^{3} \mathrm{MLCT}\right.$ and $\left.{ }^{3} \mathrm{LC}\right) .{ }^{29}$ Consequently, it is expected that the presence of two iridium centres in 2 would facilitate ISC more than the presence of a single iridium centre in 1. Emission mainly occurs from the triplet states $\left({ }^{3} \mathrm{MLCT}\right.$ and $\left.{ }^{3} \mathrm{LC}\right)$ for both the sensitizers. During the emission scans, $\mathrm{N}_{2}$ gas was purged through the sample solutions after each addition of $\mathrm{MV}^{2+}$ to minimize the effect of dissolved oxygen for obtaining maximum yields of the CT emissions from the triplet states.

Quenching of the emissions from two sensitizers upon the addition of $\mathrm{MV}^{2+}$ was compared via a Stern-Volmer plot using the equation, $I_{0} / I=1+K[\mathrm{Q}]$, where $I_{0}$ is the emission intensity in absence of a quencher, $I$ is the emission intensity in presence of a quencher, $K$ is the Stern-Volmer quenching constant, and [Q] is the quencher concentration. From the plot of $I_{0} / I v s$. $\left[\mathrm{MV}^{2+}\right]$ (Fig. 3c), $K$ 's for 1 and 2 were found to be $220.3 \mathrm{M}^{-1}$ and $112.4 \mathrm{M}^{-1}$, respectively. Despite the fact that 2 has more ${ }^{3}$ MLCT character in its excited state than $\mathbf{1}$, electron transfer to $\mathrm{MV}^{2+}$ is found to be less efficient in $\mathbf{2}$ than that in $\mathbf{1}$ mainly due to the less approachability of the electron acceptor cations in 2.

The time-resolved fluorescence decay measurements for the two sensitizers in presence of TEOA and different concentrations of $\mathrm{MV}^{2+}$ show a decrease in the average lifetime $\langle\tau\rangle$ for both 1 and 2 (Fig. 4 and Tables 1 and 2). The average lifetime is calculated using $\langle\tau\rangle=\sum \alpha_{\mathrm{i}} \tau_{\mathrm{i}} / \sum \alpha_{\mathrm{i}}$, where $\tau_{\mathrm{i}}$ indicate the lifetimes for the individual decay components and $\alpha_{\mathrm{i}}$ are their respective
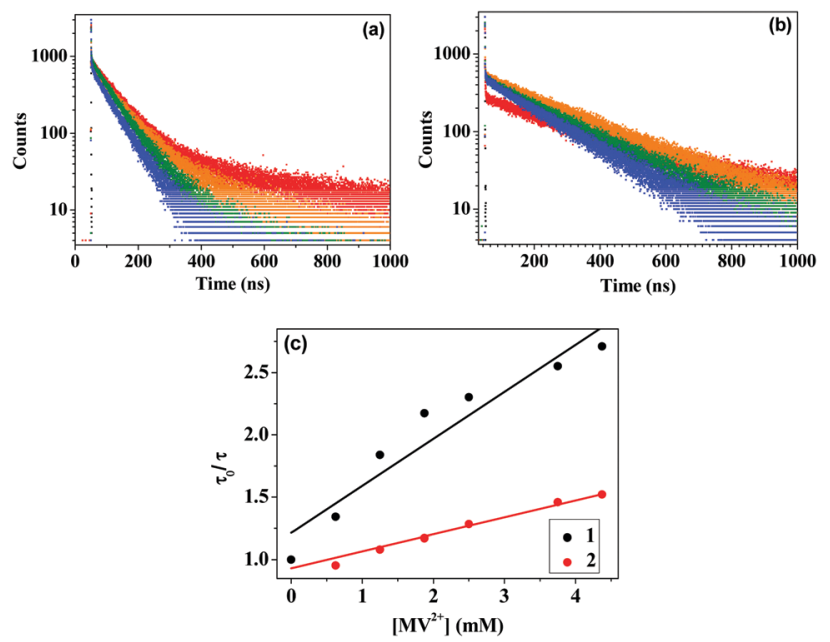

Fig. 4 Time-resolved fluorescence data of $20 \mu \mathrm{M}$ (a) $\mathbf{1}$, and (b) 2, added with $625 \mu \mathrm{M}$ TEOA and $0-4.375 \mathrm{mM}$ of $\mathrm{MV}^{2+}$; (c) Stern-Volmer quenching plots for the two complexes.

Table 1 Fluorescence lifetimes for 1 in the presence of TEOA and varying concentrations of $\mathrm{MV}^{2+}$. Values in parentheses indicate the respective percentage contributions. $\chi^{2}$ values are a measure of the goodness of the fits

\begin{tabular}{llclrl}
\hline$\left[\mathrm{MV}^{2+}\right](\mathrm{mM})$ & $\tau_{1}(\mathrm{~ns})$ & $\tau_{2}(\mathrm{~ns})$ & $\tau_{3}(\mathrm{~ns})$ & $\langle\tau\rangle(\mathrm{ns})$ & $\chi^{2}$ \\
\hline 0.0 & $0.32(1.59)$ & $372.1(28.77)$ & $72.7(69.64)$ & 157.7 & 1.05 \\
0.625 & $0.33(2.05)$ & $237.9(28.31)$ & $72.2(69.64)$ & 117.6 & 1.12 \\
1.250 & $0.33(2.00)$ & $142.1(31.84)$ & $61.3(66.16)$ & 85.8 & 1.08 \\
1.875 & $0.31(2.17)$ & $48.1(35.96)$ & $89.3(61.87)$ & 72.6 & 1.10 \\
2.500 & $0.32(3.56)$ & $40.4(24.10)$ & $81.2(72.85)$ & 68.5 & 1.13 \\
3.750 & $0.33(3.19)$ & $9.6(3.96)$ & $66.2(92.85)$ & 61.8 & 1.11 \\
4.375 & $0.36(2.26)$ & $8.4(3.17)$ & $61.2(94.57)$ & 58.2 & 1.09 \\
& & & & &
\end{tabular}

Table 2 Fluorescence lifetimes for $\mathbf{2}$ in the presence of TEOA and varying concentrations of $\mathrm{MV}^{2+}$. Values in parentheses indicate the respective percentage contributions. $\chi^{2}$ values are a measure of the goodness of the fits

\begin{tabular}{lllll}
\hline$\left[\mathrm{MV}^{2+}\right](\mathrm{mM})$ & $\tau_{1}(\mathrm{~ns})$ & $\tau_{2}(\mathrm{~ns})$ & $\langle\tau\rangle(\mathrm{ns})$ & $\chi^{2}$ \\
\hline 0.0 & $0.33(2.51)$ & $261.0(97.49)$ & 254.4 & 1.07 \\
0.625 & $0.18(1.49)$ & $271.0(98.51)$ & 266.9 & 1.01 \\
1.250 & $0.19(1.36)$ & $238.8(98.64)$ & 235.6 & 1.04 \\
1.875 & $0.19(1.67)$ & $221.2(98.33)$ & 217.5 & 1.05 \\
2.500 & $0.20(1.87)$ & $202.2(98.13)$ & 198.4 & 1.06 \\
3.750 & $0.19(1.64)$ & $177.5(98.36)$ & 174.6 & 1.09 \\
4.375 & $0.19(2.16)$ & $171.0(97.84)$ & 167.3 & 1.11
\end{tabular}

contributions. The Stern-Volmer plots obtained using the equation, $\tau_{0} / \tau=1+K[\mathrm{Q}]$, corroborate the steady state data, where $\tau_{0}$ is the lifetime of the sensitizer in the absence of $\mathrm{MV}^{2+}$, $\tau$ is the lifetime of the sensitizer in the presence of $\mathrm{MV}^{2+}, K$ is the Stern-Volmer quenching constant, and $[\mathrm{Q}]$ is the concentration of $\mathrm{MV}^{2+}$. From the plot of $\tau_{0} / \tau v s$. [ $\mathrm{MV}^{2+}$ (Fig. $4 \mathrm{c}$ ), $K$ 's for 1 and 2 were calculated to be $377.4 \mathrm{M}^{-1}$ and $135.2 \mathrm{M}^{-1}$, respectively. The third component $\tau_{3}$ appears in 1 because of the existence of the aldehyde functionality that may generate a CT state. $\langle\tau\rangle$ decreases much faster in the case of $\mathbf{1}$ as compared to that in the case of $\mathbf{2}$ due to more favourable electron transfer in the first case. 

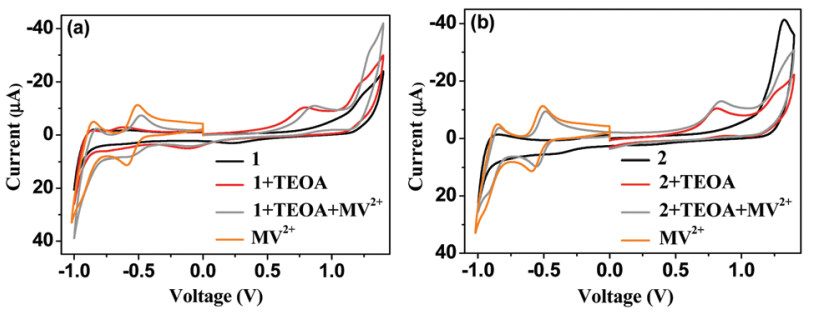

Fig. 5 Cyclic voltammograms of $\mathbf{1}$ and $\mathbf{2}$ in the absence and presence of TEOA and $\mathrm{MV}^{2+}$

Oxidative electron transfer in $\mathbf{1}$ and $\mathbf{2}$ was confirmed through electrochemical studies. A CV study allowed us to understand the details of the ground state electronic movements in the coordination complexes in the absence and presence of TEOA and $\mathrm{MV}^{2+}$ (Fig. 5). 1 and 2 show irreversible oxidation peaks at around $1.25 \mathrm{~V}$ and $1.32 \mathrm{~V}$, respectively, which are attributed to the oxidation of the iridium centres, $\operatorname{Ir}($ III) $\rightarrow \operatorname{Ir}($ IV). In the presence of TEOA, new oxidation peaks arise for both $\mathbf{1}$ and $\mathbf{2}$ at around $0.78 \mathrm{~V}$ and $0.81 \mathrm{~V}$, respectively. Hence, 2 shows an oxidation peak $30 \mathrm{mV}$ higher than that of $\mathbf{1}$. These low voltage oxidation peaks probably appear due to ligand oxidations. It is useful to note here that upon the addition of TEOA, the solution becomes alkaline (pH 8-10 depending upon the amount of TEOA added to the solution). Hence, the $-\mathrm{NH}$ on the ligand can get deprotonated by the base, leaving a net negative charge on the $\mathrm{N}$-atom. This is the origin of the oxidation peaks for the ligand. The structure of 1 suggests more electron density on the $\mathrm{N}$-atom as compared to that of $\mathbf{2}$ as the benzaldehyde moiety has an electron pushing effect and in 2, there is greater room for the delocalization of the electron density. This makes $\mathbf{1}$ more oxidizable as compared to 2, as suggested by the voltage.

The solutions of 1 and 2 turn blue upon irradiation with $370 \mathrm{~nm}$ light, suggesting the formation of $\mathrm{MV}^{\bullet+}$. Note that in absence of TEOA, no blue coloration appears. This can be explained in terms of partial neutralization of the net positive charge of the complexes due to the addition of TEOA that, otherwise, restricts the approach of the electron acceptor $\mathrm{MV}^{2+}$. This effect is more pronounced in monopositive $\mathbf{1}$ as compared to the dipositive 2. Furthermore, the iridium oxidation peaks shift to $1.21 \mathrm{~V}$ and $1.26 \mathrm{~V}$ for 1 and 2 , respectively. In the presence of TEOA, the electron density significantly increases on the ancillary ligands, and hence, oxidation becomes much easier.

The formation and existence of the $\mathrm{MV}^{\bullet+}$ radical in solution was established via flash photolysis experiments in the presence of the sacrificial donor TEOA (Fig. 6). The transient absorption spectrum for $\mathbf{1}$ shows a ground state bleach at around $350 \mathrm{~nm}$, one sharp positive absorption band at $400 \mathrm{~nm}$, and a broad band at around $550 \mathrm{~nm}$ (Fig. 6a). These are indicative of the excited ${ }^{3}$ MLCT species. The absorption decays with time at the abovementioned three wavelengths (Fig. 6b). $\mathrm{MV}^{\circ+}$ shows characteristic absorption bands at 390 and $605 \mathrm{~nm}$. In the presence of TEOA and $\mathrm{MV}^{2+}$, growth components are observed at $400 \mathrm{~nm}$ and $600 \mathrm{~nm}$, respectively, which are indicative of $\mathrm{MV}^{{ }^{++}}$(Fig. 6d). ${ }^{30,31}$ Similar observations for 2 also confirm the
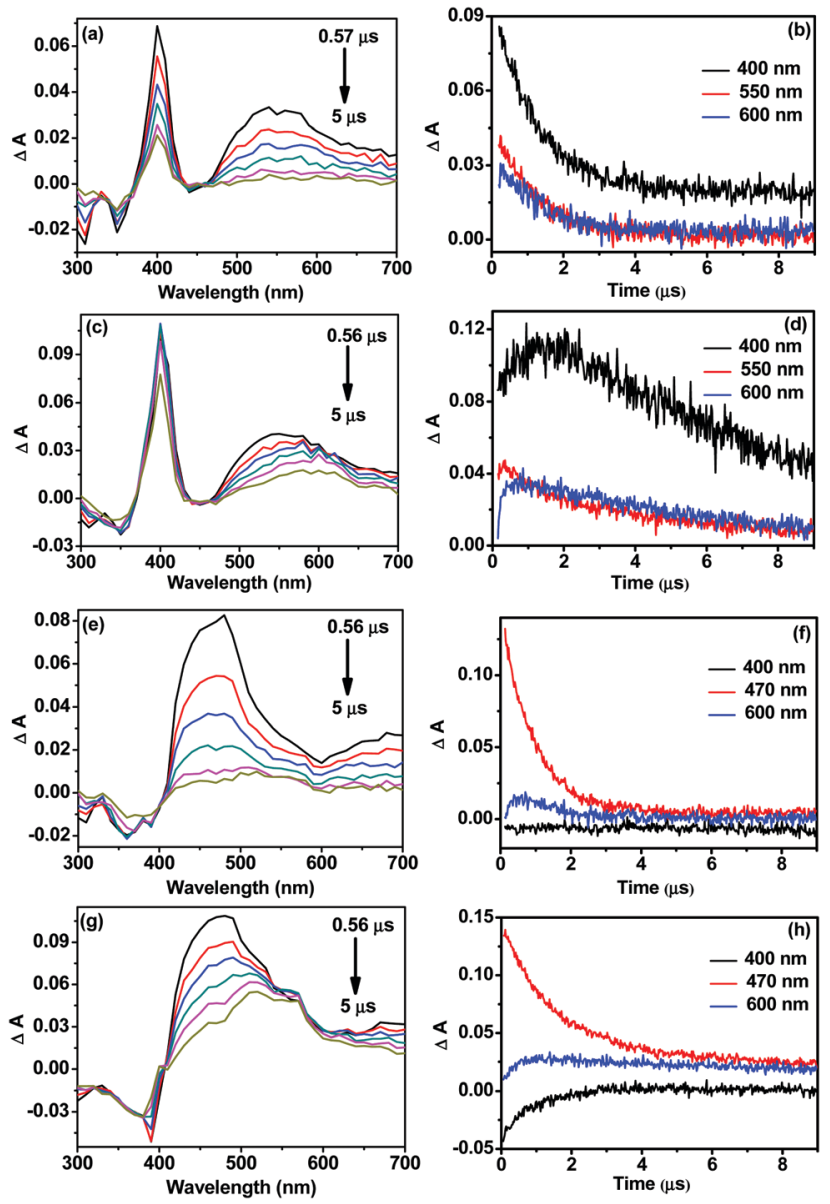

Fig. 6 Flash photolysis data for $\mathbf{1}(\mathrm{a}-\mathrm{d})$ and $\mathbf{2}(\mathrm{e}-\mathrm{h})$ showing the corresponding transient absorption spectra and decays in the absence ( $b$ and $f$ ) and presence ( $d$ and $h$ ) of TEOA and $\mathrm{MV}^{2+}$.

formation of $\mathrm{MV}^{\bullet+}$ in this case. Hence, conversion of $\mathrm{MV}^{2+}$ to $\mathrm{MV}^{\circ+}$ under the present experimental conditions provides evidence for efficient PET in $\mathbf{1}$ and $\mathbf{2}$ in the presence of TEOA and $\mathrm{MV}^{2+}$, in concurrence with the steady state data.

\section{Conclusions}

Herein, a comparative study was carried out to understand the effect on PET due to the presence of one or two iridium centres in a coordination complex. For this purpose, we synthesized Ir complexes and analyzed them spectroscopically. The high spin-orbit coupling constant for $\operatorname{Ir}\left(3909 \mathrm{~cm}^{-1}\right)$ makes the nonradiative ISC feasible. Although the excited state lifetime of $\mathbf{2}$ is higher than that of $\mathbf{1}$ due to its more stable structure, the latter becomes a more efficient electron donor in the excited state due to other factors. The presence of a sacrificial electron donor (TEOA) and a potential electron acceptor, $\mathrm{MV}^{2+}$, makes PET feasible in the presence of $370 \mathrm{~nm}$ radiation. The absence of TEOA does not allow ready availability of the acceptor in the vicinity of the complexes due to electrostatic repulsion; hence, no $\mathrm{MV}^{\circ+}$ formation is observed (no blue coloration of the solution). TEOA makes the solutions of $\mathbf{1}$ and $\mathbf{2}$ alkaline and the net positive 
charge on the complexes is significantly suppressed significantly to facilitate the approachability of $\mathrm{MV}^{2+}$ and hence favours PET. Electrochemical analysis shows that $\mathbf{1}$ is more easily oxidized than 2 in the presence of TEOA, making the monometal-centred 1 a better candidate for PET than the bimetallic 2 .

\section{Experimental}

\section{Materials}

The precursor materials $\operatorname{IrCl}_{3} \cdot 3 \mathrm{H}_{2} \mathrm{O}, 2$-phenylpyridine (ppy), 1,10-phenanthroline, and terephthalaldehyde were purchased from Sigma-Aldrich and used as received. Solvents used for synthetic purposes were of analytical grade. The spectroscopic measurements were conducted using spectroscopy grade solvents. The cyclometalated iridium(III) chloro-bridged dimer $\left[\operatorname{Ir}(\mathrm{ppy})_{2} \mathrm{Cl}\right]_{2}$, 1,10-phenanthroline-5,6-dione, 2-(4-formylphenyl)imidazo[4,5$f][1,10]$-phenanthroline (fmp), and 2,2-p-phenylene(imidazo[4,5$f][1,10]$-phenanthroline $)\left(\mathrm{H}_{2} \mathrm{bpib}\right)$ were synthesized according to literature procedures. ${ }^{19,32}$

\section{Syntheses}

The compounds 1 and $\mathbf{2}$ were synthesized following previously reported procedures. ${ }^{26}$ Both complexes were precipitated by adding potassium hexafluorophosphate $\left(\mathrm{KPF}_{6}\right)$ in $1: 1$ dichloromethanemethanol at room temperature and purified by silica gel column chromatography using a 1-10\% methanol in dichloromethane mixture. Orange-yellow coloured complexes were obtained and the structures were confirmed by ${ }^{1} \mathrm{H}$-NMR spectroscopy and ESI-MS.

\section{Instruments and methods}

The UV-visible spectra were obtained using a Hitachi U-2900 double beam spectrophotometer. Herein, $400 \mu \mathrm{L}$ of $20 \mu \mathrm{M} 1$ was taken in a micro quartz cuvette in $1: 1$ acetonitrile-water mixture for the experiments. To this, triethanolamine (TEOA), which is a sacrificial electron donor, was added $([$ TEOA $]=625 \mu \mathrm{M})$ followed by the addition of methyl viologen $\left(\mathrm{MV}^{2+}\right)$, which acts as an electron acceptor $\left(\left[\mathrm{MV}^{2+}\right]=100 \mu \mathrm{M}\right) \cdot \mathrm{N}_{2}$ gas was purged through the solution for 15 minutes to remove dissolved oxygen, and absorbance was obtained by exposing the solution to a continuum $75 \mathrm{~W}$ xenon lamp with different exposure times from 0 to 180 seconds at $370 \mathrm{~nm}$. A similar procedure was followed for 2 . The corresponding emission spectra were obtained using a PTI QuantaMaster-40 spectrofluorometer.

The fluorescence lifetimes for the respective systems were obtained using a Horiba Jobin Yvon time-resolved spectrofluorimeter with picoseconds time resolution using the timecorrelated single-photon counting (TCSPC) method. The instrument is furnished with a FluoroHub single photon counting controller and a FC-MCP-50SC MCP-PMT detection unit. The samples were excited by a $377 \mathrm{~nm}$ laser head and emission was monitored at $590 \mathrm{~nm}$. The fluorescence decay was obtained with the gradual addition of $\mathrm{MV}^{2+}(0-4.375 \mathrm{mM})$ after purging the solutions with $\mathrm{N}_{2}$ gas for 15 minutes before each measurement. The same procedure was followed for 2 .
Cyclic voltammetry (CV) was performed using a potentiostat/ galvanostat (model 263A) from Princeton Applied Research equipped with a cell stand from BASi. A Ag/AgCl reference electrode, Pt-wire counter electrode, and Pt-disc working electrode were used in this experiment. Herein, $4 \mathrm{ml}$ of $1 \mathrm{mM} 1$ solution in $1: 1$ acetonitrile-water was put into a glass container. An excess amount of tetrabutylammonium perchlorate (about $170 \mathrm{mg}$ ) was added to this solution, followed by purging with $\mathrm{N}_{2}$ for 15 minutes. The cyclic voltammogram was obtained for the system at a $50 \mathrm{mV} \mathrm{s}^{-1}$ scan rate. The same process was followed for the other solutions.

The nanosecond flash photolysis setup obtained from Applied Photophysics comprising a Nd:YAG laser (Lab series, Model Lab 150, Spectra Physics) was used for obtaining the transient absorption spectra. Samples were excited at $355 \mathrm{~nm}$ using the Nd:YAG laser. Then, $25 \mu \mathrm{M}$ of 1 in $2 \mathrm{ml}$ of $1: 1$ acetonitrile-water was placed in a cuvette, and the solution was degassed by purging with argon gas for 20 minutes. Transient absorption spectra were obtained using a continuum $150 \mathrm{~W}$ xenon lamp placed perpendicularly to the laser beam. Spectra for the solution containing $25 \mu \mathrm{M}$ of $1,250 \mu \mathrm{M}$ of $\mathrm{MV}^{2+}$, and $500 \mu \mathrm{M}$ of TEOA were similarly obtained. The same procedure was followed for 2 .

\section{Acknowledgements}

SKS is thankful to the Council of Scientific and Industrial Research for a Senior Research Fellowship. This work is supported by the Department of Science and Technology through research grants ST/FT/CS-057/2009 (PG) and EMR/2015/000950 (PP). The authors thank Prof. Samita Basu of Saha Institute of Nuclear Physics for allowing the flash photolysis experiments.

\section{Notes and references}

1 I. M. Dixon, J. P. Collin, J. P. Sauvage, L. Flamigni, L. S. Encinas and F. Barigelletti, Chem. Soc. Rev., 2000, 29, 385-391.

2 C. Ulbricht, B. Beyer, C. Friebe, A. Winter and U. S. Schubert, Adv. Mater., 2009, 21, 4418-4441.

3 M. A. Baldo, M. E. Thompson and S. R. Forrest, Nature, 2000, 403, 750-753.

4 Highly Efficient OLEDs with Phosphorescent Materials, ed. H. Yersin, Wiley-VCH, Berlin, 2007.

5 A. F. Henwood, A. K. Bansal, D. B. Cordes, A. M. Z. Slawin, I. D. W. Samuelb and E. Zysman-Colman, J. Mater. Chem. C, 2016, 4, 3726-3737.

6 X. Yang, X. Xu, J. S. Dang, G. Zhou, C. L. Ho and W. Y. Wong, Inorg. Chem., 2016, 55, 1720-1727.

7 E. Baranoff, J. H. Yum, M. Graetzel and M. K. Nazeeruddin, J. Organomet. Chem., 2009, 694, 2661-2670.

8 Z. Ning, Q. Zhang, W. Wu and H. Tian, J. Organomet. Chem., 2009, 694, 2705-2711.

9 Q. Zhao, C. Huang and F. Li, Chem. Soc. Rev., 2011, 40, 2508-2524. 
10 Q. Zhao, M. Yu, L. Shi, S. Liu, M. Shi, Z. Zhou, C. Huang and F. Li, Organometallics, 2010, 29, 1085-1091.

11 C. H. Lin, Y. Y. Chang, J. Y. Hung, C. Y. Lin, Y. Chi, M. W. Chung, C. L. Lin, P. T. Chou, G. H. Lee, C. H. Chang and W. C. Lin, Angew. Chem., Int. Ed., 2011, 50, 3182-3186.

12 S. Lee, S. O. Kim, H. Shin, H. J. Yun, K. Yang, S. K. Kwon, J. J. Kim and Y. H. Kim, J. Am. Chem. Soc., 2013, 135, 14321-14328.

13 S. Mondal, S. K. Seth, P. Gupta and P. Purkayastha, J. Phys. Chem. C, 2015, 119, 25122-25128.

14 S. Serroni, S. Campagna, G. Denti, A. Juris, M. Venturi and V. Balzani, J. Am. Chem. Soc., 1994, 116, 9086-9091.

15 L. Hammarström, F. Barigelletti, L. Flamigni, M. T. Indelli, N. Armaroli, G. Calogero, M. Guardigli, A. Sour, J. P. Collin and J. P. Sauvage, J. Phys. Chem. A, 1997, 101, 9061-9069.

16 M. Maestri, N. Armaroli, V. Balzani, E. C. Constable and A. M. W. C. Thompson, Inorg. Chem., 1995, 34, 2759-2767.

17 L. F. Gildea and J. A. G. Williams, Organic Light-Emitting Diodes: Materials, Devices and Applications, ed. A. Buckley, Woodhead, Cambridge, U.K., 2013.

18 R. A. Marcus and N. Sutin, Biochim. Biophys. Acta, 1985, 811, 265-322.

19 H. Chao, R.-H. Li, C.-W. Jiang, L.-N. Ji and X.-Y. Li, J. Chem. Soc., Dalton Trans., 2001, 1920-1926.

20 P. Srinivasan, R. H. Mason, J. R. G. MacNeil and B. J. MacLean, Inorg. Chim. Acta, 2011, 366, 116-121.

21 F. Gao, H. Chao, F. Zhou, B. Peng and L.-N. Ji, Inorg. Chem. Commun., 2007, 10, 170-173.
22 L. Flamigni, A. Barbieri, C. Sabatini, B. Ventura and F. Barigelletti, Photochemistry and Photophysics of Coordination Compounds: Iridium, in Topics in Current Chemistry, ed. V. Balzani, S. Campagna, Springer, 2007, 281, 143-203.

23 B. Gholamkhass, K. Koike, N. Negishi, H. Hori, T. Sano and K. Takeuchi, Inorg. Chem., 2003, 42, 2919-2932.

24 G. F. Manbeck, E. Fujita and J. J. Concepcion, J. Am. Chem. Soc., 2016, 138, 11536-11549.

25 F. Gao, X. Chen, F. Zhou, L.-P. Weng, L.-T. Guo, M. Chen, H. Chao and L.-N. Ji, Inorg. Chim. Acta, 2009, 362, 4960-4966.

26 S. K. Seth, S. Mandal and P. Purkayastha, Polyhedron, 2015, 95, 14-23.

27 E. E. Méndez, C. Crespo-Hernández, R. Figueroa, R. Arce and E. Quiñones, J. Photochem. Photobiol., A, 2001, 142, 19-24.

28 V. Martínez-Junza, A. Rizzi, K. A. Jolliffe, N. J. Head, M. N. Paddon-Row and S. E. Braslavsky, Phys. Chem. Chem. Phys., 2005, 7, 4114-4125.

29 S. Y. Takizawa, K. Shimada, Y. Sato and S. Murata, Inorg. Chem., 2014, 53, 2983-2995.

30 G. F. Manbeck, E. Fujita and J. J. Concepcion, J. Am. Chem. Soc., 2016, 138, 11536-11549.

31 S. Takizawa, K. Shimada, Y. Sato and S. Murata, Inorg. Chem., 2014, 53, 2983-2995.

32 S. Sprouse, K. A. King, P. J. Spellane and R. J. Watts, J. Am. Chem. Soc., 1984, 106, 6647-6653. 